\title{
Magnetron Sputtering Coating of Protective Fabric Study on Influence of Thermal Properties
}

\author{
Yunqi Zhai, Xiaoxia Liu, Li Xiao \\ College of Fashion, Shanghai University of Engineering Science, Shanghai, China \\ Email: zhaily1102@163.com
}

Received 29 October 2015; accepted 27 November 2015; published 30 November 2015

Copyright (C) 2015 by authors and Scientific Research Publishing Inc.

This work is licensed under the Creative Commons Attribution International License (CC BY).

http://creativecommons.org/licenses/by/4.0/

(c) (i) Open Access

\begin{abstract}
Protective fabric has been the focus of research of the textile materials. In recent years, with the rapid development of the robot, its protective fabric has been developed quickly. This paper is making $\mathrm{Al}, \mathrm{SiO}_{2}$ as the sputtering target materials, magnetron sputtering as technology, on the back of the fabric sputtering $\mathrm{Al}$ layer, double-layer $\mathrm{Al} / \mathrm{SiO}_{2}$ film, and three-layer $\mathrm{SiO}_{2} / \mathrm{Al} / \mathrm{SiO}_{2}$ film through the test of the heat reflectivity of the composite materials. As a result, the highest reflectivity of the $\mathrm{SiO}_{2} / \mathrm{Al} / \mathrm{SiO}_{2}, \mathrm{SiO}_{2} / \mathrm{Al}$, and single $\mathrm{Al}$ film is $64.97 \%, 57.38 \%$, and $51.59 \%$, respectively. It is clear that reflectivity increases with the increase of the membrane layer. In three kinds of membrane structures, there are nanometer Al particles in the formation of dense membrane structure, which can improve the reflectivity of the fabric.
\end{abstract}

\section{Keywords}

Magntron Sputtering, Heat Reflectance, Nano-Film

\section{Introduction}

Al has very good heat reflectivity, low pollution, high electrical conductivity characteristics [1], and it has good adhesion with silicon substrates, $\mathrm{SiO}_{2}$ and $\mathrm{TiO}_{2}$ [2], but they all have a common flow which is easily oxidized. $\mathrm{TiO}_{2}$ is a kind of colorless, odorless, and white filling; it is non-toxic, high UV-resistant shielded, high refractive index, strong light scattering, high stability and oxidation ability and so on [3], and it has a good reflection for near infrared rays of the sun. Making $\mathrm{TiO}_{2}$ as a dielectric layer, because the valence band of $\mathrm{TiO}_{2}$ is making up of oxygen 2 p band and conduction band is mainly titanium $3 \mathrm{~d}$, the band gap width (about $3 \mathrm{eV}$ ), the visible light is almost no absorption. When the visible light through the $\mathrm{TiO}_{2}$ reaches the reflective layer, the introduction of $\mathrm{TiO}_{2}$ medium layer can keep the reflection layer effective for a long time. $\mathrm{SiO}_{2}$ thin films have a low refractive 
index $(\mathrm{n}=1.458)$, good transmittance, and the $\mathrm{SiO}_{2}$ films also have good insulation, stability and mechanical properties, high hardness, fine structure, strong film, anti corrosion, and high melting point [4], which indicate that $\mathrm{SiO}_{2}$ is especially suitable for the protection layer of reflective metal film. $\mathrm{SiO}_{2}$ thin films have been widely used in the fields of semiconductor, microwave, optoelectronics, optical devices and thin film sensors for its excellent properties.

This paper is based on the use of aramid fiber as the substrate material, using the method of magnetron sputtering coating on the fabric, so that the fabric has a heat insulation cooling effect. Metal film is by DC magnetron sputtering technique, the high pure aluminum as the sputtering target material; non metal film is by RF magnetron sputtering technique, $\mathrm{SiO}_{2}$ or $\mathrm{TiO}_{2}$ as the sputtering target material. In this experiment, high purity argon was used as the gas, and sputtering the single film of the $\mathrm{Al}$ and $\mathrm{Ag}$, double layer $\mathrm{SiO}_{2} / \mathrm{Al}$, three layer $\mathrm{SiO}_{2} / \mathrm{Al} / \mathrm{SiO}_{2}$ nano particles were sprayed on the fabric by controlling the sputtering power and sputtering time. At last, the surface of the thin film was studied by SEM, XRD and so on. The microstructure of the thin film was studied. The effect of the different structure of the film was obtained by comparison.

\section{Tests and Procedures}

\subsection{Preparation of Sample}

Selected fabrics was cut into $15 \times 15 \mathrm{~cm}$ square, into a beaker of acetone solution, in ultrasonic instrument for cleaning for $30 \mathrm{~min}$, followed by deionized water cleaning 3 - 5 times to basically smell the irritating smell. Then clean the fabric into the oven at 100 degrees 30 min or so, until the fabric weight is not changed. In order to make the sputtering film and substrate material have a better combination, the dry fabric with plasma machine for processing, in order to remove some impurities on the original, and finally iron will be smooth.

The fabric is fixed on the working table of the magnetron sputtering coating machine, the closed chamber is closed and sealed. The mechanical pump is opened, and the molecular pump is pumped to $5.0 \times 10^{-4} \mathrm{~Pa}$, and the chamber is heated to the setting temperature, and the thermal equilibrium time is $1800 \mathrm{~s}$. After the temperature is stable, high purity argon (concentration of 99.99\%), and adjust the preset pressure, a 200W DC power supply for the first 3 min pre sputtering and remove the baffle of sample sputtering time. This process samples always to min speed rotation to keep the sputtering uniformity (the selected experimental parameters are after a lot of experiments using orthogonal experiment was used to optimize the parameters, seeing Table 1). After sputtering, close the DC power supply, and open the pump and the mechanical arm of the pump and the mechanical arm to clean the cavity chamber of the gas (pumping time at least $6 \mathrm{~min}$ ). After the chamber temperature dropped to 80 degrees Celsius, close the pumping gas channel, open the gas valve (time $3 \mathrm{~min}$ ) to get rid of the chamber vacuum, open the chamber to remove the specimen.

\subsection{Structure and Characterization}

The surface appearance of the prepared sample with S-3400N scanning electron microscope, the resolution of the scanning electron microscope is $4 \mathrm{~nm}$, the magnification is 30000 times, and the accelerating voltage is $5 \mathrm{kV}$ - $15 \mathrm{kV}$. X'PERT por type X-ray diffraction were used to characterize the film crystal structure, test conditions for $\mathrm{Cu}$ Target $\mathrm{K}$ alpha, the Ni filter, tube voltage $40 \mathrm{kV}$, tube current $40 \mathrm{~mA}$, determination of wavelength lambda $=0.15418 \mathrm{~nm}$, sweep range is 2 theta (5 DEG to 90 DEG), scanning speed for 0.8 sec/step. Japan Shimadzu Corporation UV-3600 UV-vis-IR spectrophotometer, $\mu \mathrm{m}$ film in 0.5 radiation in the wavelength range of reflectivity test using United States Thermo Nicolet's AVATAR370 FTIR spectrophotometer, the sample wave

Table 1. Test of process parameter.

\begin{tabular}{cccc}
\hline Membrane structure & $\mathrm{Al}$ & $\mathrm{SiO}_{2} / \mathrm{Al}$ & $\mathrm{SiO} / \mathrm{Al}^{-\mathrm{SiO}_{2}}$ \\
\hline Pressure (Pa) & 0.8 & $0.5 / 0.8$ & $30 / 30 / 30$ \\
Sputtering time (min) & 30 & $30 / 30$ & $200 / 200 / 200$ \\
Sputtering power (W) & 200 & $200 / 200$ & $60 / 40 / 60$ \\
Ar rate of flow (sccm) & 10 & $60 / 40$ & $200 / 150 / 200$ \\
Temperature $\left({ }^{\circ} \mathrm{C}\right)$ & 150 & $200 / 150$ & 2000 \\
\hline
\end{tabular}


number in $400-4000 \mathrm{~cm}^{-1}$ (2.5 - $25 \mu \mathrm{m}$ wavelength) tested the reflectivity. ATR, the samplers are OMNISAMPLERTM, scan 32 times, data interval is $1.929 \mathrm{~cm}^{-1}$, and the resolution is $8 \mathrm{~cm}^{-1}$.

\section{Results and Discussion}

\subsection{Surface Topography}

Aramid fabrics with improved process parameters on single layer of aluminium sputtering thin film and its surface as shown in Figure 1(a), Figure 1(b); Al thin films in air is a highly oxidizing substance, to improve the heat reflective aluminum film effects, well plated aluminum top layer and $\mathrm{SiO}_{2}$ is protected, its surface as shown in Figure 1(c), Figure 1(d); three-layer membrane structure morphology of $\mathrm{SiO}_{2} / \mathrm{Al} / \mathrm{SiO}_{2}$ as shown in Figure 1(e), Figure 1(f).

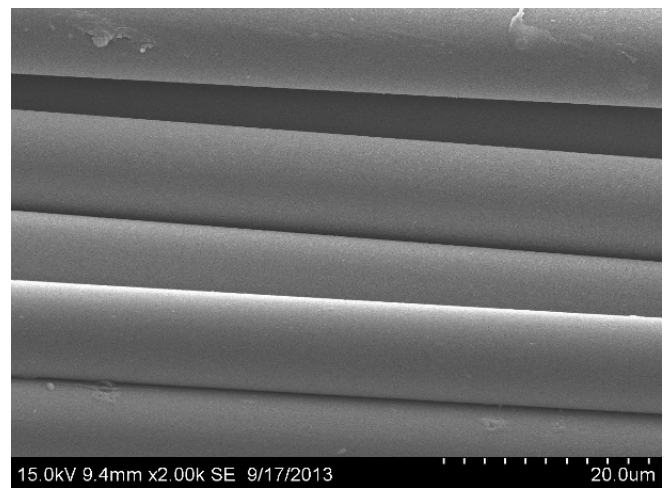

(a)

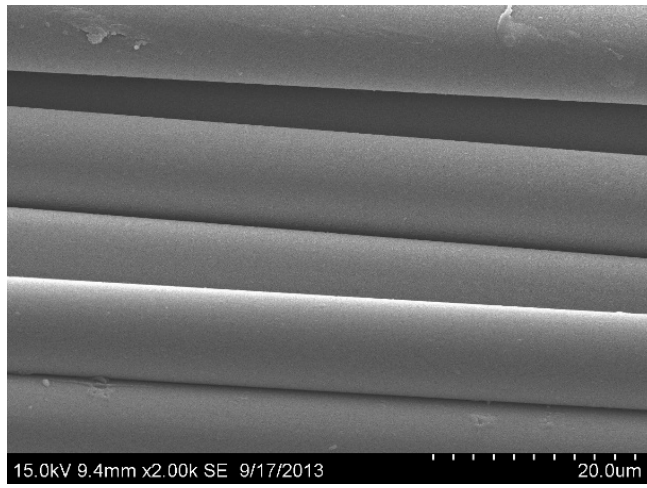

(c)

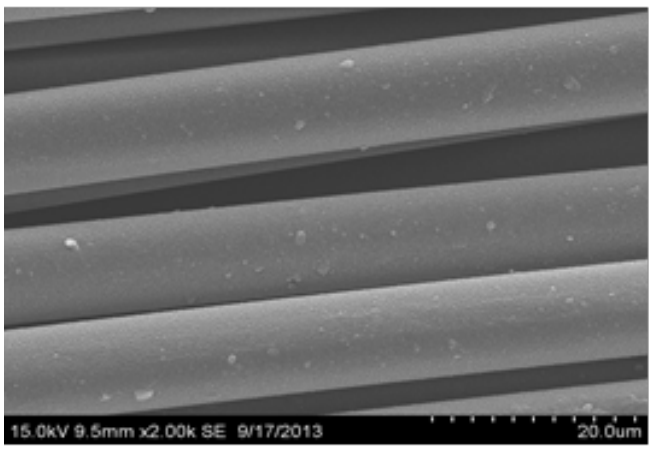

(e)

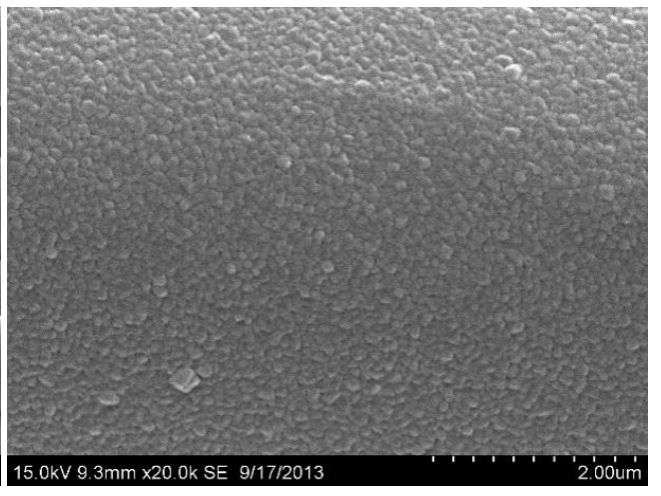

(b)

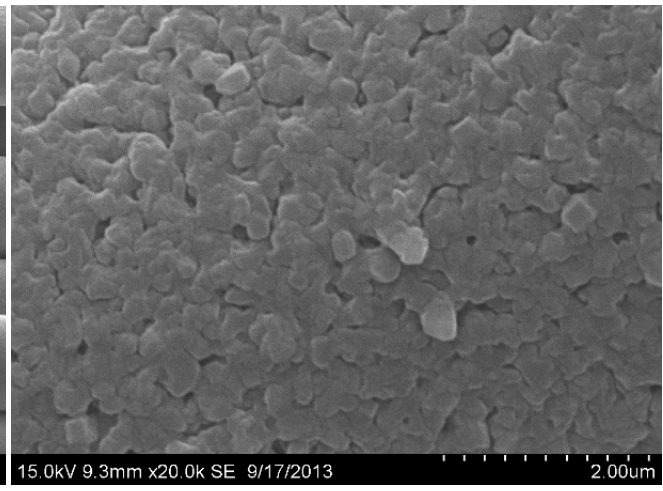

(d)

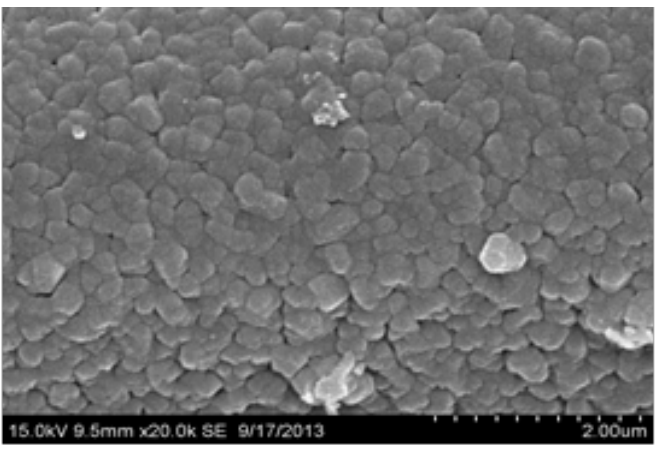

(f)

Figure 1. Single and double layer plated Al coating aramid fabric SEM. (a) Monolayer film 2 K SEM; (b) Monolayer film 10 K SEM; (c) Double-layer film 2 K SEM; (d) Double-layer film 10 K SEM; (e) Three-layer film 2 K SEM; (f) Three-layer film 10 K SEM. 
From the 2 K SEM which can be seen in the figure, on the whole, three kinds of coating process on the fiber surface forming a dense homogeneous membrane structure. And it could be seen most single-layer membrane structure of Al surface smooth, mirror-like effect; double $\mathrm{SiO}_{2} / \mathrm{Al}$ surface although smooth but granular is also significantly bigger. From 10 K SEM figure you can see that single layer of Al film surface for Al small spherical particles, even thin film is formed on the surface, we can see that Al-membrane structure formation can be used to form a mirror effect to anti-thermal radiation requirements. $\mathrm{SiO}_{2} / \mathrm{Al}$ bilayer surface particle becomes large, flat geometry and particle shape, surface flatness is better. Three $\mathrm{SiO}_{2} / \mathrm{Al} / \mathrm{SiO}_{2}$ surface layer of $\mathrm{SiO} \mathrm{O}_{2}$ is grainy, but its size gets bigger. Poor smoothness of the film than the other two, there are several points in the larger agglomeration.

In general, all three kinds of membrane structure on the fiber surface forming a continuous dense film structure. Viewed from the surface, single film of Al the most smooth, metal fine particles on the surface; $\mathrm{SiO} / \mathrm{Al}$ bilayer surface is smooth but larger particle size than single-layer membrane. Three layers of $\mathrm{SiO}_{2} / \mathrm{Al} / \mathrm{SiO}_{2}$ surface roughness decrease, and in some places the phenomenon of particle agglomeration.

\subsection{XRD Measurement and Analysis}

Figure 2 shows the three kinds of XRD diagrams of structural films. It can be clearly seen from the three film structure, $2 \theta$ respectively for, $38.51^{\circ}, 44.75^{\circ}, 65.11^{\circ}$, it has obviously peak after and elemental aluminum of standard (JCPDS cards 652869) compared, respectively for Al corresponds to of (111), (200), (220) three a features peak, $78.29^{\circ}$ at has weaker of $\mathrm{Al}$ (311) of features peak, description three species film structure in the are contains metal Al of components. By XRD analysis, Scherrer, Paul formula calculates the average grain size of Al film. Scherrer, Paul formula, where $\mathrm{D}$ is the average grain diameter and $\lambda$ is the wavelength of $\mathrm{x}$-diffraction, $\beta$ is the most intense diffraction peak FWHM, in radians, and $\theta$ is the diffraction angle. Computed in single layer of Al film $\mathrm{Al}$ an average particle size of about $28 \mathrm{~nm}$; $\mathrm{SiO}_{2} / \mathrm{Al}$ two-layer membrane structure of the average particle size is also about to $28 \mathrm{~nm} ; \mathrm{SiO}_{2} / \mathrm{Al} / \mathrm{SiO}_{2}$ film structure characteristic peaks in the first three Al calculated an average particle size of about $29 \mathrm{~nm}$. As can be seen in different film structure, little has changed of Al particles with an average diameter. Target interface in the coating process on different surface coating process of particles in particle size has not changed. In $15^{\circ}-35^{\circ}$ between the main diffraction peak is the outer layer of $\mathrm{SiO}_{2}$.

\subsection{Analysis of Reflectivity}

\subsubsection{UV-Vis-IR Spectrophotometer Analysis}

Figure 3 shows the UV-vis-IR reflectance spectra. From Figure 3, the reflectivity of single film of $\mathrm{Al}$ and reflectivity of the double $\mathrm{SiO}_{2} / \mathrm{Al}$ is close, and three-layer $\mathrm{SiO}_{2} / \mathrm{Al} / \mathrm{SiO}_{2}$ to low reflectance of the membranes, reflectance is low. When the analysis shows that when the $\mathrm{SiO}_{2}$ is the outermost, thermal radiation passes the outer layer of $\mathrm{SiO}_{2}$ on the absorption of thermal radiation has some, particularly in the ultraviolet and visible region is more obvious, resulted in multilayer reflectivity reflectance than the single layer film but declined.

As shown in Table 2, through the integrals are obtained in three films in the $250 \mathrm{~nm}-2500$ nm range of reflectivity: single film $\mathrm{Al}$ is $64.26 \%$, double $\mathrm{SiO}_{2} / \mathrm{Al}$ film is $63.73 \%$, three-layer $\mathrm{SiO}_{2} / \mathrm{Al} / \mathrm{SiO}_{2}$ film is $53.93 \%$. As can be seen in three films in the wavelengths of thermal radiation for $250-2500 \mathrm{~nm}(0.25$ - $2.5 \mu \mathrm{m})$ range with heat-reflecting ability, single-layer and double-layer membrane structure of membrane structure was three-layer membrane structure with better reflective properties.

\subsubsection{Reflection Fourier Transform Infrared Measurement and Analysis}

Figure 4 and Table 3 show that in three films in the mid-infrared region $(2.5-25 \mu \mathrm{m})$ reflectivity similar to overall downward trend as the radiation wavelength increases. $\mathrm{SiO}_{2} / \mathrm{Al} / \mathrm{SiO}_{2}$ film in $4000 \mathrm{~cm}^{-1}-1100 \mathrm{~cm}^{-1}(2.5$ $-9.09 \mu \mathrm{m})$ range of reflectivity is slightly higher than the other two films, $1100 \mathrm{~cm}^{-1}-400 \mathrm{~cm}^{-1}(9.09-25 \mu \mathrm{m})$ within the reflectance has decreased, but still slightly higher than the single layer of Al film.

\section{Table 2. UV-vis-IR reflectance.}

\begin{tabular}{cccc}
\hline Membrane structure & $\mathrm{Al}$ & $\mathrm{SiO}_{2} / \mathrm{Al}$ & $\mathrm{SiO}_{2} / \mathrm{Al}_{/} \mathrm{SiO}_{2}$ \\
\hline Reflectivity (\%) & $64.26 \%$ & $63.73 \%$ & $53.93 \%$ \\
\hline
\end{tabular}




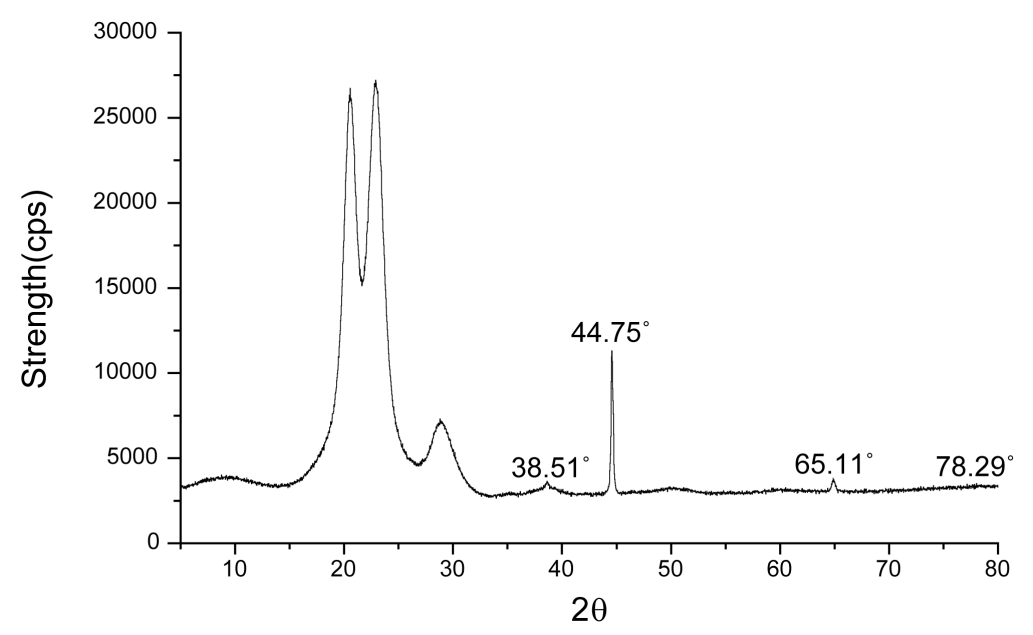

(a)

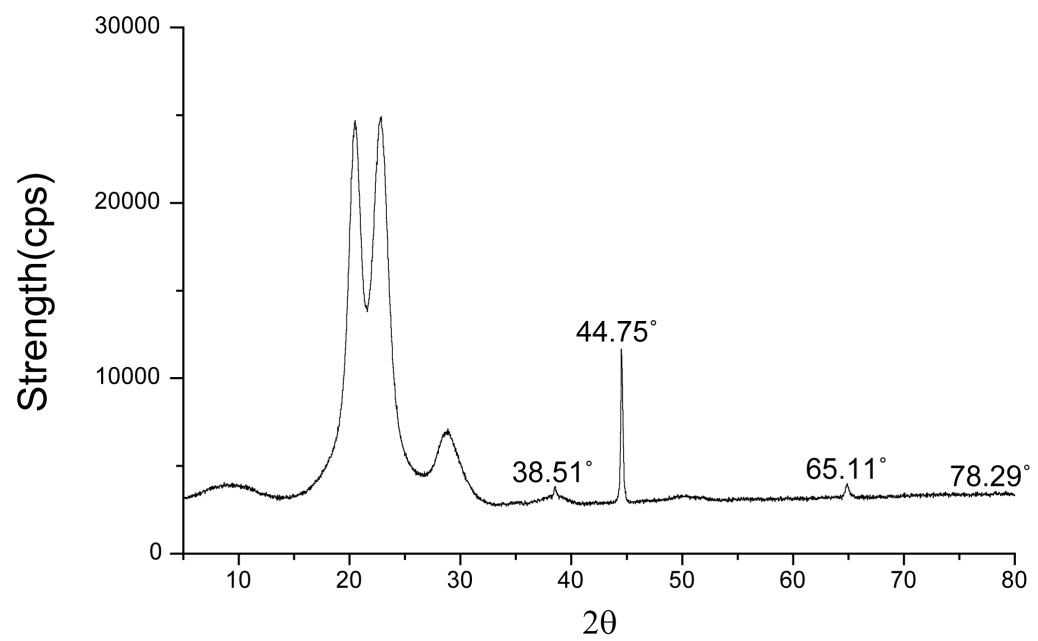

(b)

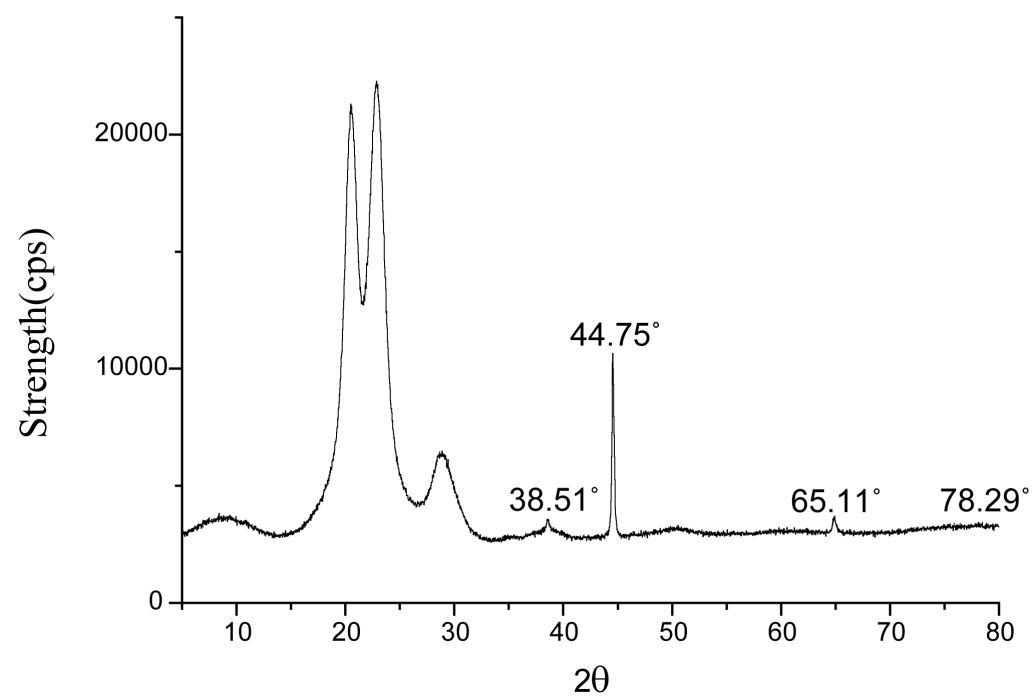

(c)

Figure 2. Three kinds of XRD diagrams of structural films. (a) Al-film XRD graph; (b) $\mathrm{SiO}_{2} / \mathrm{Al}$-film XRD graph; (c) $\mathrm{SiO}_{2} / \mathrm{Al} / \mathrm{SiO}_{2}$-film XRD graph. 


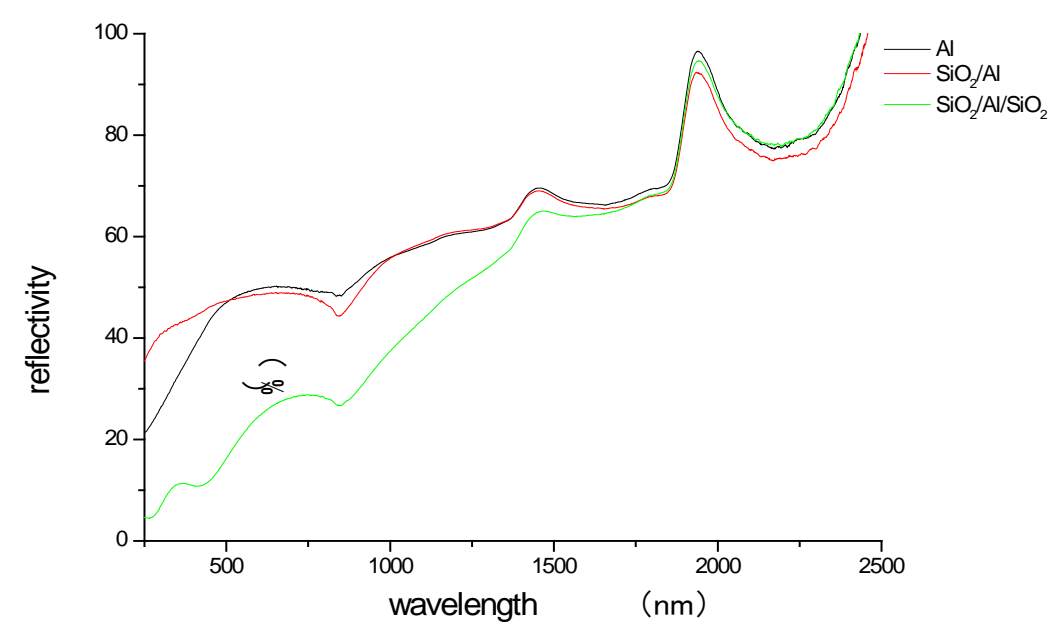

Figure 3. UV-vis-IR reflectance spectra.

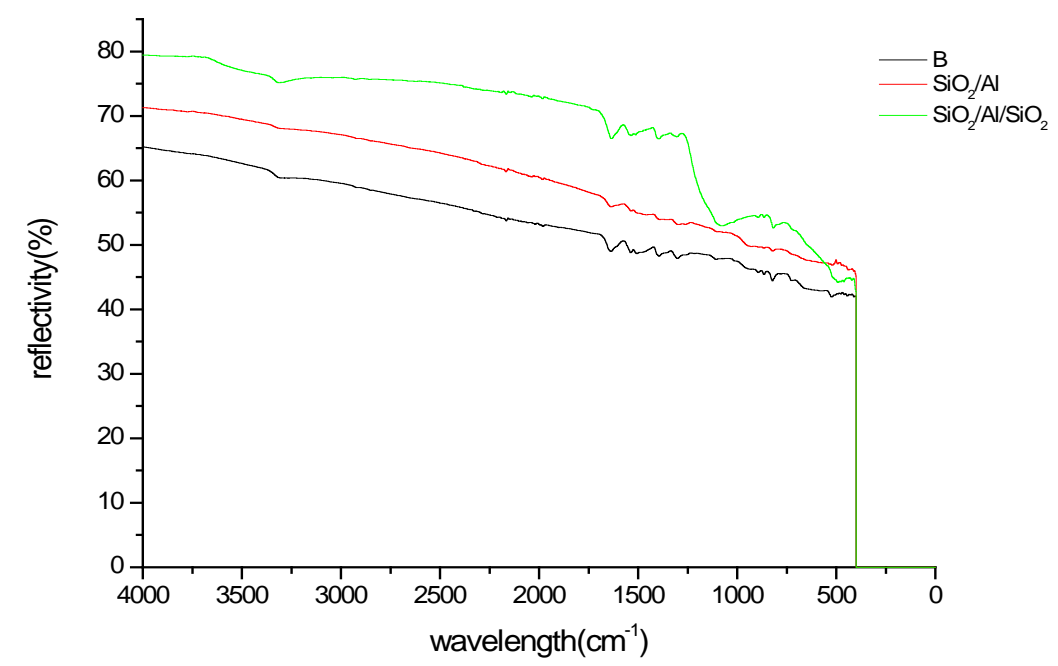

Figure 4. Reflectance Fourier transform infrared spectrum.

Table 3. Fourier transform infrared reflectance.

\begin{tabular}{cccc}
\hline Membrane structure & $\mathrm{Al}$ & $\mathrm{SiO}_{2} / \mathrm{Al}$ & $\mathrm{SiO}_{2} / \mathrm{Al} / \mathrm{SiO}_{2}$ \\
\hline Reflectivity (\%) & 56.68 & 63.05 & 71.41 \\
\hline
\end{tabular}

From Table 4 we can see the integrated FTIR spectrophotometer UV-vis-IR spectrophotometer data calculated from three kinds of membrane structure fabric 0.25 - $25 \mu \mathrm{m}$ within the total reflectance. Results are shown in Table 3, General $\mathrm{SiO}_{2} / \mathrm{Al} / \mathrm{SiO}_{2}$ of three-layer membrane reflects the highest rate, followed by $\mathrm{SiO}_{2} / \mathrm{Al}$ bilayer membrane, single film of $\mathrm{Al}$ least apparent reflectance increases with the increase of the number of film layers.

\subsection{Protection against Heat Radiation Performance}

From Figure 5 you can see that after magnetron sputtering coating fabrics in varying degrees of temperature difference between before and after the upgrade, suggests lining heat insulation and heat radiation performance improves. Among them, Al single layer and three-layer $\mathrm{SiO}_{2} / \mathrm{Al} / \mathrm{SiO}_{2}$ fabric side eventually reached 11 degrees Celsius temperature difference showed better protection against heat radiation performance. $\mathrm{SiO}_{2} / \mathrm{Al}$ bilayer sides fabric fabric temperature stable at $6^{\circ} \mathrm{C}$ instead of coating aramid fabric around the same temperature. 
Table 4. Total reflectance.

\begin{tabular}{cccc}
\hline Membrane structure & $\mathrm{Al}$ & $\mathrm{SiO}_{2} / \mathrm{Al}$ & $\mathrm{SiO}_{2} / \mathrm{Al} / \mathrm{SiO}_{2}$ \\
\hline Reflectivity (\%) & 51.59 & 57.38 & 64.97 \\
\hline
\end{tabular}

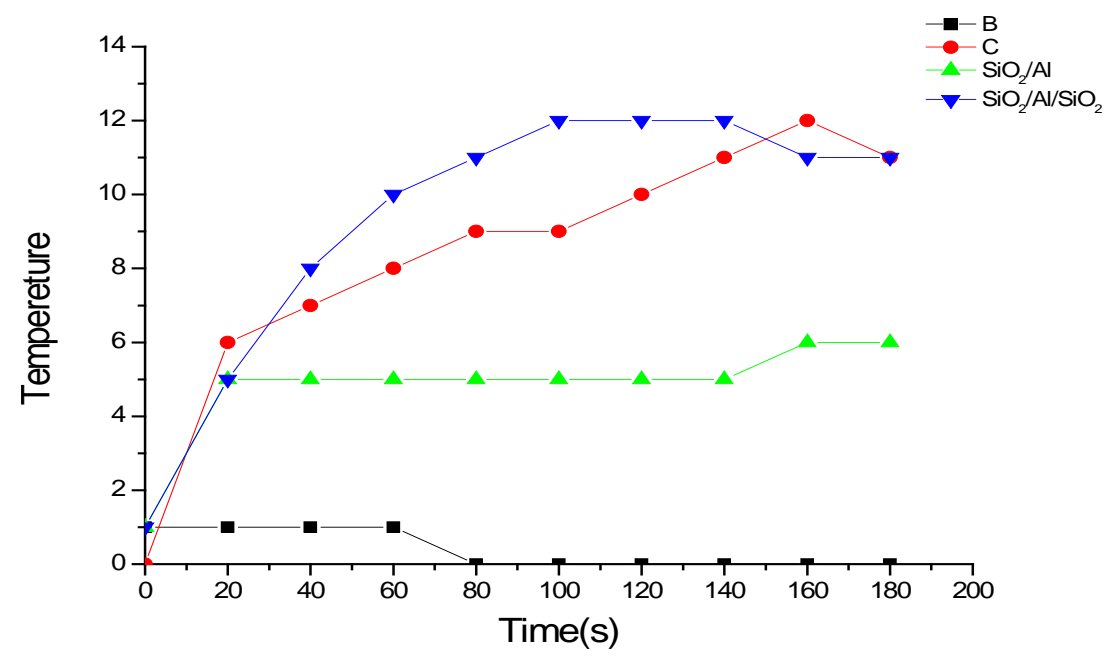

Figure 5. The fabric temperature before and after comparison chart.

\section{Conclusions}

$\mathrm{Al}$ from the ultraviolet $(0.2 \mu \mathrm{m})$ to infrared $(30 \mu \mathrm{m})$ has a high reflectivity (near $0.85 \mu \mathrm{m}$ reflectivity, about 85\%), and it can be processed into a variety of shapes of plate, foil and evaporated film [5]. In addition, aluminum film surface always has a layer of transparent $\mathrm{Al}_{2} \mathrm{O}_{3}$ film, and the film is widely used as a reflection of various types of reflective film [6]. The morphology, structure and heat resistance of the PSA surface are changed by sputtering $\mathrm{Al}$ film, double $\mathrm{SiO}_{2} / \mathrm{Al}$ film, and three layers of $/ \mathrm{SiO}_{2}$.

1) By SEM observation of the surface of different film structure, it is found that the surface of the fabric is composed of nano scale $\mathrm{Al}$ and $\mathrm{SiO}_{2}$ particles. The surface of the $\mathrm{Al}$ film is smooth, and the metal particles are the most fine. The surface of the double layer $\mathrm{SiO}_{2} / \mathrm{Al}$ film and the three layer $/ \mathrm{SiO}_{2} \mathrm{SiO}_{2} / \mathrm{Al}$ film is rough; the surface grain size is large.

2) Through the XRD test of different membrane structures, the characteristics of $\mathrm{Al}$ are clearly shown in the map, which can be concluded that the structure of the film contains $\mathrm{Al}$ elements. The particle size of $\mathrm{Al}$ in three kinds of membrane structures is about $28 \mathrm{~nm}$.

3) According to the three kinds of fabric thermal performance test, from the 0.25 - $25 \mu \mathrm{m}$, the maximum reflectivity of the three-layer film $\left(\mathrm{SiO}_{2} / \mathrm{Al} / \mathrm{SiO}_{2}\right)$, double-layer film $\left(\mathrm{SiO}_{2} / \mathrm{Al}\right)$, and single-layer film $(\mathrm{Al})$ is $64.97 \%$, $57.38 \%$, and $51.59 \%$, respectively. It is clear that reflectivity increases with the increase of the membrane layer. In the same infrared thermal radiation source with testing the fabric before and after temperature, the heat radiation performance of the three kinds of coated fabrics has been significantly improved, and the temperature difference between the front and back of the sputtered material can reach $11^{\circ} \mathrm{C}$.

\section{References}

[1] Hamasha, M.M., Alzoubi, K., Switzer III, J.C., et al. (2011) A Study on Crack Propagation and Electrical Resistance Change of Sputtered Aluminum Thin Film on Poly Ethylene Terephthalate Sub-Strate under Stretching. Thin Solid Films, 519, 7918-7924. http://dx.doi.org/10.1016/j.tsf.2011.06.062

[2] Yang, D.H. (2006) On the Technological Parameters Deposition of Al Thin Films by DC Magnetron Sputtering. Journal of Chongqing Institute of Technology, 20, 69-71.

[3] Wang, K.L. and Chen, K.N. (2009) Insulation Mechanism of Titanium Dioxide and Its Application in Functional Fabrics. Modern Textile Technology, 1, 59-62.

[4] Zeng, Q.Y. and Zheng, X.F. (2009) $\mathrm{SiO}_{2}$ Film Review of Current Methods of Producing. Vacuum, 4, 36-40. 
[5] Cai, Q.W. (2012) The Performance of High Reflectivity Solar Reflective Materials and the Design of the Membrane System. South China University of Technology, Guangzhou.

[6] Yin, Z.Z., Xu, M., Li, L., Yan, C.H., Jie, B.W., Wu, C.H. and Qiu, J.W. (2008) Magnetron Sputtering Method Prepared High Reflecting Aluminum Film. Vacuum and Low Temperature, 3, 164-166. 